\title{
Regulation of the integrin aV $\beta 3$ - actin filaments axis in early osteogenesis of human fibroblasts under cyclic tensile stress
}

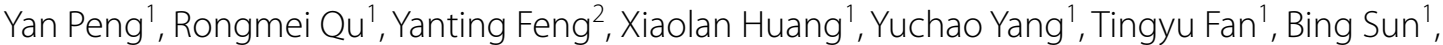 \\ Asmat Ullah Khan', Shutong Wu' ${ }^{1}$, Jingxing Dai ${ }^{1^{*}} \mathbb{D}$ and Jun Ouyang ${ }^{1^{*}}$
}

\begin{abstract}
Background: Integrins play a prominent role in osteogenic differentiation by transmitting both mechanical and chemical signals. Integrin expression is closely associated with tensile stress, which has a positive effect on osteogenic differentiation. We investigated the relationship between integrin aV 33 and tensile stress.

Methods: Human fibroblasts were treated with c (RGDyk) and lentivirus transduction to inhibit function of integrin aVß3. Y-15, cytochalasin D and verteporfin were used to inhibit phosphorylation of FAK, polymerization of microfilament and function of nuclear YAP, respectively. Fibroblasts were exposed to a cyclic tensile stress of $10 \% \mathrm{at} 0.5 \mathrm{~Hz}$, once a day for $2 \mathrm{~h}$ each application. Fibroblasts were harvested on day 4 and 7 post-treatment. The expression of ALP, RUNX2, integrin aV $\beta 3$, $\beta$-actin, talin-1, FAK, vinculin, and nuclear YAP was detected by Western blot or qRT-PCR. The expression and distribution of integrin aV $\beta 3$, vinculin, microfilament and nuclear YAP.

Results: Cyclic tensile stress was found to promote expression of ALP and RUNX2. Inhibition of integrin aV $\beta 3$ activation downregulated the rearrangement of microfilament and the expression of ALP, RUNX2 and nuclear YAP. When the polymerization of microfilament was inhibited the expression of ALP, RUNX2 and nuclear YAP were decreased. The phosphorylation of FAK induced by cyclic tensile stress reduced by the inhibition of integrin aV $\beta 3$. The expression of ALP and RUNX2 was decreased by inhibition of phosphorylation of FAK and inhibition of nuclear YAP.
\end{abstract}

Conclusions: Cyclic tensile stress promotes osteogenesis of human fibroblasts via integrin aVß3-microfilament axis. Phosphorylation of FAK and nuclear YAP participates in this process.

Keywords: Osteogenesis, Integrin aV $\beta 3$, Tensile stress, Cellular mechanotransduction, Fibroblast

\section{Introduction}

Large bone defects (with a fracture space $>2.5 \mathrm{~cm}$ ), whether caused by trauma, tumors, or infection, require external bone repair. Bone grafting is the currently favored approach to repairing large bone defects, but it has several drawbacks, including limited source material

\footnotetext{
*Correspondence: daijx@smu.edu.cn; jouyang@smu.edu.cn ${ }^{1}$ Guangdong Provincial Key Laboratory of Medical Biomechanics and Department of Anatomy, School of Basic Medical Science, Southern Medical University, Guangzhou 510000, China

Full list of author information is available at the end of the article
}

and donor site morbidity [1-3]. An alternative approach is bone tissue engineering, which uses biomaterials and stem cells that can be easily propagated and induced to differentiate into osteocytes that contribute to new bone formation $[4,5]$.

Fibroblasts are a common adherent cell type within the mesenchymal stroma [6]. Fibroblasts and mesenchymal stem cells have similar MSC markers and can differentiate into cells of osteogenic, adipogenic, and chondrogenic lineages $[7,8]$. In fibrodysplasia ossificans progressiva model, Micha D et al. have observed that fibroblasts from original author(s) and the source, provide a link to the Creative Commons licence, and indicate if changes were made. The images or other third party material in this article are included in the article's Creative Commons licence, unless indicated otherwise in a credit line to the material. If material is not included in the article's Creative Commons licence and your intended use is not permitted by statutory regulation or exceeds the permitted use, you will need to obtain permission directly from the copyright holder. To view a copy of this licence, visit http://creativecommons.org/licenses/by/4.0/. The Creative Commons Public Domain Dedication waiver (http://creativeco mmons.org/publicdomain/zero/1.0/) applies to the data made available in this article, unless otherwise stated in a credit line to the data. 
patients show an enhanced potential for osteogenic differentiation in agreement with the heterotopic ossification characterizing this disease [9]. In another approach, the subcutaneous ectopic bone formation in mice after implantation of the epigenetically modified fibroblasts [10]. Further, differentiation of fibroblasts toward the osteoblast lineage was also demonstrated with treatment of osteoclast-conditioned media, and TGF- $\beta$ was shown to improve the capacity of fibroblasts for osteogenic differentiation [11, 12]. The similarities of fibroblasts and mesenchymal stem cells support the use of fibroblasts as an appropriate cell type to study osteogenesis [13]. When stem cells are in a microenvironment composed of biomaterials, growth factors and tissues, the appropriate mechanical stimuli can promote osteogenic differentiation of stem cells [14]. Clinical and basic studies have shown that external mechanical stimulation, such as increased tension in response to stretch, can affect osteogenic differentiation of stem cells $[15,16]$. Mechanotransduction is the process by which mechanical stimuli are converted into biochemical signals, often via integrins, which then affect downstream cellular activities [17].

Integrins are transmembrane receptors that exist on the cell surface and are functional heterodimers composed of $\alpha$ and $\beta$ subunits linked by non-covalent bonds $[18,19]$. Integrins mediate connections between cells and the extracellular matrix, from which mechanical stimulation can be transduced into the cell via integrins, which then initiate and regulate intracellular osteogenic signaling pathways [20, 21]. Integrins bind to extracellular matrix ligands via their large extracellular domains and to the cytoskeleton via short unstructured cytoplasmic tails capable of interacting with multiple intracellular proteins. Aggregation and activation of integrins recruit and activate intracellular signaling proteins such as focal adhesion kinase (FAK), vinculin and talin, which contribute to focal adhesions and influence differentiation of stem cells [22-24].

Yes-associated protein (YAP) is a transcriptional coactivator that promotes cell proliferation and regulates differentiation of stem cells by binding to TEAD (TEA domain DNA-binding family of transcription factors) DNA-binding proteins that can control transcription [25-27]. Studies have shown that manipulation of F-actin levels through knockdown of regulators of the actin cytoskeleton or treatment with F-actin-inhibitory drugs significantly affects YAP activity [28]. However, how mechanical stimulation influences YAP through the integrin-microfilament axis to regulate stem cell osteogenic differentiation remains unclear.

We investigated the relationship between integrin $\alpha \mathrm{V} \beta 3$ and early stage of osteogenic differentiation induced by cyclic tensile stress (CTS). Activation of integrin $\alpha \mathrm{V} \beta 3$ leads to rearrangement of actin filaments and regulated the expression of nuclear YAP. We also found that FAK participated in the formation of focal adhesions, and phosphorylation of FAK mediated by integrin $\alpha \mathrm{V} \beta 3$ played a role in early stage of osteogenic differentiation induced by CTS. This study shows that integrin $\alpha \mathrm{V} \beta 3$ may serve as a therapeutic target for bone repair.

\section{Materials and methods \\ Chemicals and reagents}

$\mathrm{c}$ (RGDyk) $(10 \mu \mathrm{M}$, dissolve in medium) was purchased from Selleck (Shanghai, China). RGD (10 $\mu \mathrm{M}$, dissolve in medium) and RGE (10 $\mu \mathrm{M}$, dissolve in medium) peptides were purchased from A-Peptide (Shanghai, China). $\mathrm{Y}-15(2 \mu \mathrm{M}$, dissolve in medium), cytochalasin D (Cyto $\mathrm{D}, 0.2 \mu \mathrm{g} / \mathrm{mL}$, dissolve in DMSO) and verteporfin (VP, $5 \mu \mathrm{M}$, dissolve in medium) were purchased from MedChemExpress (NJ, the USA).

\section{Cell culture}

Human skin fibroblasts were purchased from ScienCell research laboratories (San Diego, CA, the USA, Cat \#2320) and isolated from adult human skin. Human skin fibroblasts were cultured in DMEM (Gibco, Grand Island, NY, the USA) at $37{ }^{\circ} \mathrm{C}$ in a $5 \% \mathrm{CO}^{2}$ atmosphere. The medium was supplemented with $10 \%$ heat-inactivated fetal bovine serum (Gibco) and 1\% mixture of penicillin and streptomycin (Gibco). The 11th generation of fibroblasts will be used in subsequent experiments.

After $48 \mathrm{~h}$ of cell passage, all inhibitors were applied for $24 \mathrm{~h}$, followed by tensile stress. During stretching, the medium which include inhibitors should be changed every 2 days to maintain the working concentration.

\section{Tensile stress loading}

Cells were plated at a density of $1 \times 10^{5}$ cells per dish on collagen I-coated silicone membrane plates (Bioflex, Flexcell International, NC, the USA) and cultured for 2 days before beginning experiments. Cyclic tensile stress was applied to fibroblasts plated on six-well Bioflex Collagen I-coated plates using the Flexcell FX-5000 system (Flexcell International). A regimen of $10 \%$ tensile strain was delivered at $0.5 \mathrm{~Hz}$ for $2 \mathrm{~h}$ each day. Cells used for CCK8 and ALP (alkaline phosphatase) staining, Western blotting, qRT-PCR and immunofluorescence were processed immediately after application of cyclic tensile stress. Cells cultured under similar conditions but without cyclic stretch were used as unstretched controls.

\section{ALP staining}

Cells were washed twice with phosphate-buffered saline (PBS) and fixed for 15 min with 4\% paraformaldehyde. Thereafter, the cells were rinsed twice with PBS and 
added to an ALP reaction solution (Beyotime, Shanghai, China). After incubation for $30 \mathrm{~min}$ at $37^{\circ} \mathrm{C}$, the reaction solution was removed, and the cells were rinsed twice with PBS. The stained cells were observed under optical microscope (OLYMPUS, Japan).

\section{CCK8 experiment}

Cells were rinsed twice with PBS and added to a CCK8 reaction solution (Beyotime). After incubation for $1 \mathrm{~h}$ at $37^{\circ} \mathrm{C}$, the absorbance of reaction solution was detected by microplate reader.

\section{Lentivirus transduction}

Green fluorescent protein-labeled plasmid vectors (negative control (NC)) (Cat \#CON077), hsa-ITG-AV (integrin $\alpha \mathrm{V}$ ) (Cat \#51830) and hsa-ITG-B3 (integrin $\beta 3$ ) (Cat \#16375) were synthesized and packaged into lentivirus by Shanghai GeneChem Co. Ltd. Cell suspensions were prepared at a density of $1 \times 10^{4}$ cells $/ \mathrm{mL}$ growth medium (GM), and $2 \mathrm{~mL}$ was seeded into a 6-well plate. After $24 \mathrm{~h}$, when the cell density reached $30-40 \%$, GM supplemented with $40 \mu \mathrm{L} / \mathrm{mL}$ HistransG P and lentivirus (multiplicity of infection 40) was added to each well. After $12 \mathrm{~h}$, the medium was changed, and the cells were incubated for 3 days. The extent of transfection was observed under an inverted phase-contrast fluorescence microscope on the fifth day. To screen successfully transfected cells, the medium was changed to GM containing $3 \mu \mathrm{g} / \mathrm{mL}$ puromycin for 3 days. After 3 days of screening with puromycin, fibroblasts were replaced with growth medium and cultured normally.

\section{RNA extraction and quantitative real-time PCR}

Total cellular RNA was extracted using Trizol lysis buffer. RNA was reverse transcribed to cDNA using the Qiagen (Shanghai, China) miRNA reverse transcription (miScript II RT Kit) and thermo reverse transcription kits. Expression of integrin $\alpha \mathrm{V}$, integrin $\beta 3$, ALP, RUNX2, Talin-1, FAK, vinculin, $\beta$-actin and GAPDH was detected by quantitative real-time PCR (qRT-PCR) by using cDNA as a template. The qRT-PCR was performed using an ABI 7500 qRT-PCR system (Applied Biosystems). The specific primer sequences used are shown in Table 1.

\section{Western blot analysis}

Cells were harvested and washed twice with PBS. Cellular protein was extracted using radio-immunoprecipitation assay lysis buffer. Protein was separated by $10 \%$ SDS polyacrylamide gel electrophoresis and transferred onto polyvinylidene difluoride (PVDF) membranes. The PVDF membranes were removed and blocked with 5\% $(\mathrm{w} / \mathrm{v})$ skimmed milk powder for $1 \mathrm{~h}$ after electrophoresis was complete. All membranes were incubated at
Table 1 Primers used in the qRT-PCR

\begin{tabular}{lll}
\hline Gene & Forward primer & Reverse primer \\
\hline GAPDH & TCGGAGTCAACGGATTTGGT & TTCCCGTTCTCAGCCTTGAC \\
RUNX2 & GAGATCATCGCCGACCAC & TACCTCTCCGAGGGCTACC \\
ALP & ACCATTCCCACGTCTTCACAT & AGACATTCTCTCGTTCACCGCC \\
& TTG & \\
ITG AV & CCGAAGCTCAGCCCTCTTG & GAAAAGCCATCGCCGAAGTG \\
ITG B3 & ACCAGTAACCTGCGGATTGG & CTCATTGAAGCGGGTCACCT \\
Talin-1 & GGAAAAGTGCGGGGATAG & CAAGAACACAGGCCGTTTGG \\
FAK & CAGGGTCCGATTGGAAACCA & CTGAAGCTTGACACCCTCGT \\
Vinculin & CGCTGAGGTGGGTATAGGTG & GTAGCTTCCCGATGCAAGGA \\
\hline
\end{tabular}

$4{ }^{\circ} \mathrm{C}$ overnight with diluted primary antibody (mouse anti-ALP [1:1000, Abcam, Cat \# ab126820], rabbit antiRUNX2 (runt-related transcription factor 2) [1:1000, Cell Signaling Technology, Cat \# 12556S], rabbit anti-betaactin [1:1000, Cell Signaling Technology, Cat \# 4970S], rabbit anti-talin1 [1:1000, Cell Signaling Technology, Cat \#4021S], mouse anti-vinculin [1:1000, Sigma, Cat \# V9131], mouse anti-FAK [1:500, Santa Cruz, Cat \# sc1688], rabbit anti-YAP [1:1000, Cell Signaling Technology, Cat \# 14074S], rabbit anti-GAPDH (glyceraldehyde-3-phosphate dehydrogenase) [1:5000, Bioworld, Cat \# ap0063]), washed and incubated with horseradish peroxidase-conjugated secondary antibody (1:5000, Beyotime) at room temperature for $1 \mathrm{~h}$. Enhanced chemiluminescence (ECL) chromogenic substrate was applied to enhance immunoreactive protein bands.

\section{Immunofluorescence analysis}

Cells were fixed in $4 \%$ paraformaldehyde solution for $15 \mathrm{~min}$ at room temperature. Then, cells were cultured with $0.1 \%$ Triton X-100 for $5 \mathrm{~min}$ at room temperature. Cells were subsequently incubated with $5 \%$ bovine serum albumin/phosphate-buffered saline (PBS) for $30 \mathrm{~min}$ at room temperature. Cells were incubated with primary antibody overnight at $4{ }^{\circ} \mathrm{C}$ (mouse anti-integrin $\alpha \mathrm{V} \beta 3$ [1:200, Millipore, Cat \# MAB1976], mouse anti-vinculin [1:200, Sigma], rabbit anti-YAP [1:200, Cell Signaling Technology], Phalloidin Red-594 [1:500, Beyotime, Cat \# C2203S]). After washing with PBS, cells were incubated with secondary antibody for $1 \mathrm{~h}$ in the dark. A fluorescence microscope was used to view and acquire images.

\section{Statistical analysis}

Statistical analysis was performed using SPSS 20.0 software (IBM, Inc. Armonk, NY, the USA). All data are presented as mean $\pm \mathrm{SD}$ of three independent experiments. Data among three or more groups were analyzed using a one-way analysis of variance with Tukey's post hoc analysis. Differences between two groups were analyzed using 
Student's $t$ test. A two-tailed value of $P<0.05$ was considered statistically significant.

\section{Results \\ Cyclic tensile stress promotes cell proliferation and osteogenesis in fibroblasts}

This study explored the association between cyclic tensile stress, cell proliferation, and osteogenic differentiation of fibroblasts. First, fibroblasts were exposed to cyclic tensile stress for $4 \mathrm{~d}$ and $7 \mathrm{~d}$. As shown in Fig. 1a, fibroblast proliferation increased in response to cyclic tensile stress. Protein and RNA expression of ALP and RUNX2, as markers of osteogenic differentiation, increased after $7 \mathrm{~d}$ under cyclic tensile stress (Fig. 1c, d). Similar results were obtained by ALP staining of fibroblasts, which was higher under cyclic tensile stress (Fig. 1b). These results suggest that cyclic tensile stress promotes cell proliferation and early stage of osteogenic differentiation in fibroblasts.

\section{Early stage of osteogenic differentiation induced by cyclic tensile stress depends on expression and activation of integrin $\mathrm{aV} \beta 3$}

To explore whether integrins are involved in osteogenic differentiation and cell proliferation induced by cyclic tensile stress, expression of integrin $\alpha \mathrm{V} \beta 3$ was analyzed in fibroblasts by qRT-PCR and immunofluorescence. We found that integrin $\alpha \mathrm{V} \beta 3$ expression increased under cyclic tensile stress (Fig. 1e, f), suggesting that cyclic tensile stress promotes expression of integrin $\alpha \mathrm{V} \beta 3$. Therefore, we investigated the association between integrin $\alpha \mathrm{V} \beta 3$ and osteogenic differentiation under cyclic tensile stress. To determine whether cyclic tensile stress stimulates osteogenic differentiation in an integrin $\alpha \mathrm{V} \beta 3$ dependent manner, the function of integrin $\alpha \mathrm{V} \beta 3$ was inhibited by shRNA or RGDyk, antagonists of integrin $\alpha \mathrm{V} \beta 3$ (Additional file 1: Fig. S1). As shown in Fig. 2a, when expression of integrin $\alpha \mathrm{V}$ or $\beta 3$ was downregulated in fibroblasts, cell proliferation decreased under cyclic tensile stress. Then, we detected the effect of integrin $\alpha \mathrm{V} \beta 3$ on osteogenic differentiation by ALP staining, western blotting and qRT-PCR. ALP staining was less in the shRNA-integrin $\alpha \mathrm{V}$ and $\beta 3$ groups than in the CTS group (Fig. 2b). Western blots showed that protein expression of ALP and RUNX2 decreased upon downregulation of integrin $\alpha \mathrm{V} \beta 3$ expression in fibroblasts (Fig. 2c, e). Similar results were obtained by qRT-PCR, with expression of ALP and RUNX2 mRNA decreasing when integrin $\alpha \mathrm{V} \beta 3$ expression was inhibited (Fig. 2d, f). Overall, these results show that cyclic tensile stress promotes early stage of osteogenic differentiation and cell proliferation of fibroblasts via integrin $\alpha \mathrm{V} \beta 3$.
Cyclic tensile stress-regulated actin filaments via integrin aV $\beta 3$ during osteogenesis

To better understand the association between integrin $\alpha \mathrm{V} \beta 3$ and actin filaments under cyclic tensile stress, we detected the expression of $\beta$-actin when integrin $\alpha \mathrm{V} \beta 3$ was inhibited. Western blotting and qRT-PCR showed that expression of $\beta$-actin increased under cyclic tensile stress (Fig. 3a, b). When expression of integrin $\alpha \mathrm{V} \beta 3$ was inhibited, expression of $\beta$-actin in the RGDyk group was lower than that in the CTS group (Fig. 3c, d). We also found that expression of $\beta$-actin in the shRNA-integrin $\alpha \mathrm{V}$ or $\beta 3$ groups was lower than that in the CTS group (Fig. 3e, f). Immunofluorescence showed that microfilament stress fibers were dispersed in a network structure close to the cell membrane under cyclic tensile stress. When expression of integrin $\alpha \mathrm{V} \beta 3$ was inhibited, microfilament stress fibers were arranged in an elongated manner similar to those in the GM group (Fig. 3h). These results suggest that cyclic tensile stress upregulates expression of $\beta$-actin and transforms the structure of actin filaments via integrin $\alpha \mathrm{V} \beta 3$.

To investigate whether actin filaments participate in osteogenic differentiation induced by cyclic tensile stress, we used cytochalasin D to inhibit polymerization of actin filaments [29, 30] (Figure S2a). Western blotting showed that expression of ALP and RUNX2 reduced by cytochalasin D under cyclic tensile stress (Fig. 3g). In summary, these results suggest that cyclic tensile stress regulates early stage of osteogenic differentiation of fibroblasts via the integrin $\alpha \mathrm{V} \beta 3$-microfilament axis.

\section{Cyclic tensile stress-regulated nuclear YAP via the integrin aV $\beta 3$-microfilament axis during osteogenesis}

We also explored whether cyclic tensile stress regulates expression of nuclear YAP via the integrin $\alpha \mathrm{V} \beta 3$ microfilament axis. Western blotting and qRT-PCR showed that expression of nuclear YAP increased under cyclic tensile stress (Fig. 4a). When expression of integrin $\alpha \mathrm{V} \beta 3$ was inhibited, western blotting showed that expression of nuclear YAP was lower than in the CTS group (Fig. 4b). The results of immunofluorescence showed that expression of nuclear YAP significantly increased under cyclic tensile stress. We also found that expression of nuclear YAP was reduced when integrin $\alpha \mathrm{V} \beta 3$ was inhibited (Fig. 4c). These results showed that cyclic tensile stress upregulated nuclear YAP via integrin $\alpha \mathrm{V} \beta 3$. When polymerization of $\beta$-actin was inhibited by cytochalasin $D$, western blotting and immunofluorescence showed that expression of nuclear YAP decreased under cyclic tensile stress (Fig. 4d, e). Western blotting also showed that expression of ALP and RUNX2 was reduced under cyclic tensile stress in 


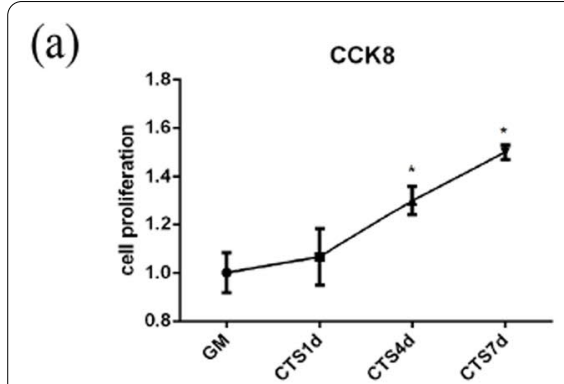

(c)

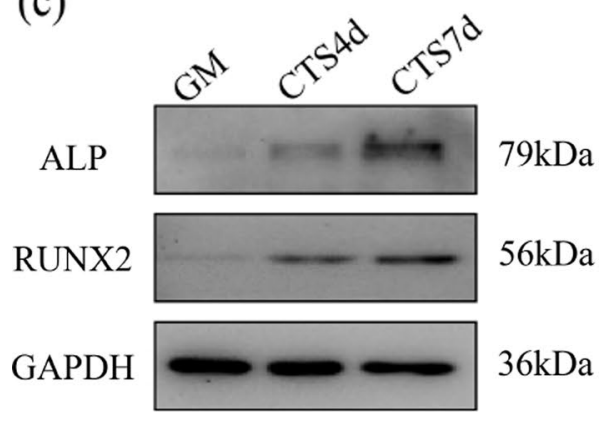

(e)
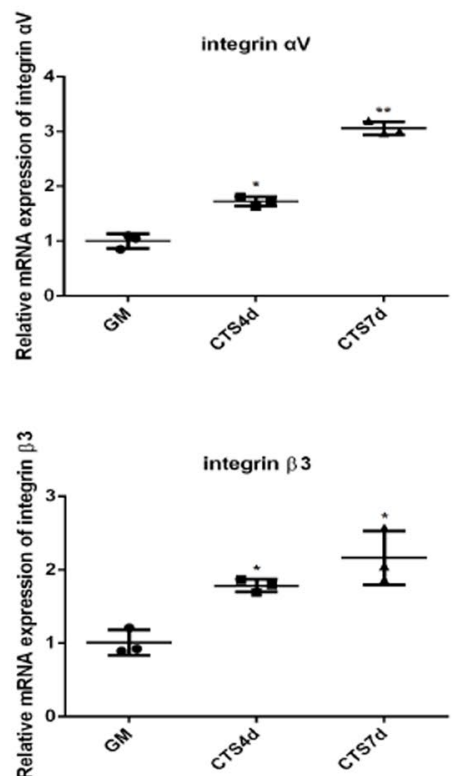

(f) (b)

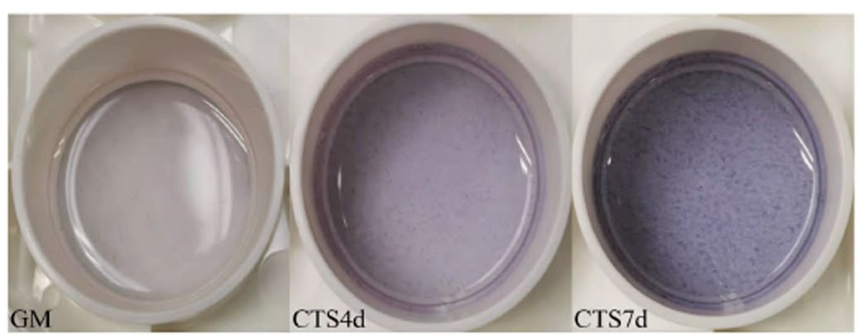

(d)
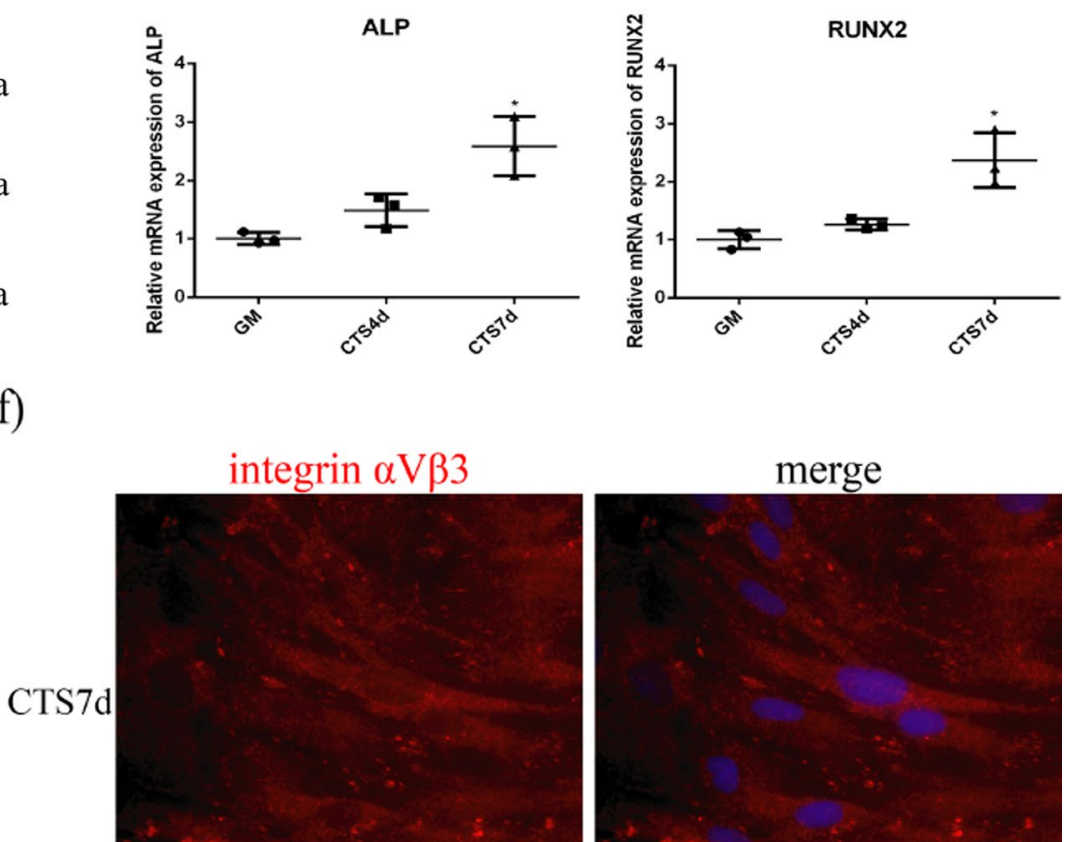

GM
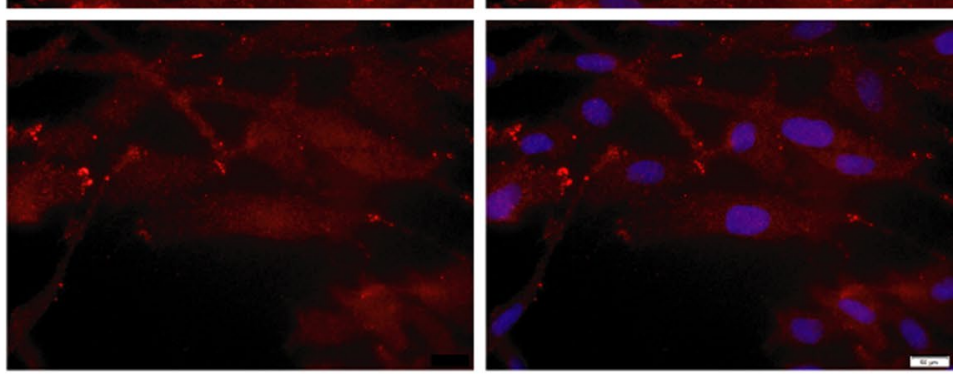

Fig. 1 Cell proliferation, early stage of osteogenic differentiation and expression of integrin aV 33 in fibroblasts under CTS. a Cell proliferation under CTS for $1 \mathrm{~d}, 4 \mathrm{~d}, 7 \mathrm{~d}$. b ALP staining under CTS for $4 \mathrm{~d}$ and $7 \mathrm{~d}$. c Protein expression of ALP and RUNX2 under CTS for $4 \mathrm{~d}$ and $7 \mathrm{~d}$. $\mathbf{d}$ mRNA expression of ALP and RUNX2 under CTS for $4 \mathrm{~d}$ and $7 \mathrm{~d}$. e mRNA expression of integrin aV 33 under CTS for $4 \mathrm{~d}$ and $7 \mathrm{~d}$. $\mathbf{f}$ Immunofluorescence of integrin aVB3 under CTS for $7 \mathrm{~d}$. Scale bar, $50 \mu \mathrm{m}$

the presence of verteporfin (Fig. 4f, Additional file 2: Fig. S2b). The above experiments show that cyclic tensile stress regulates nuclear YAP via the integrin $\alpha \mathrm{V} \beta 3$ microfilament axis during early stage of osteogenic differentiation.
Cyclic tensile stress promoted the formation of focal adhesions and FAK phosphorylation during osteogenesis Focal adhesions formed by actin filaments and integrins require talin, FAK and vinculin to transmit CTS to the substrate. We detected expression of talin-1, FAK and 
(a)

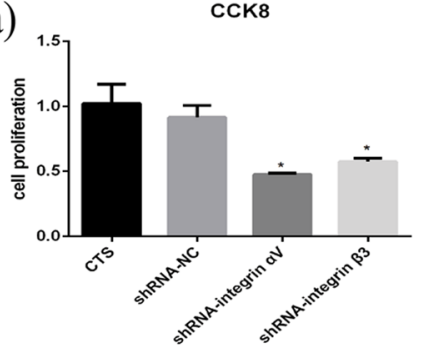

(c)

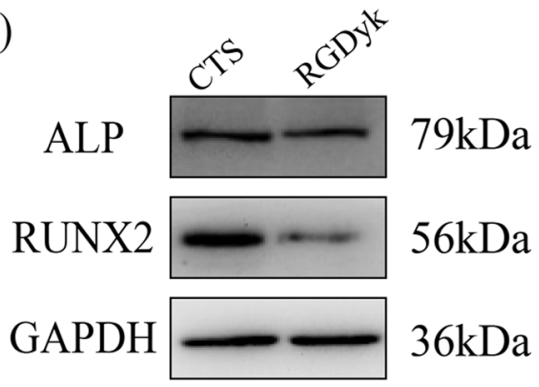

(e)

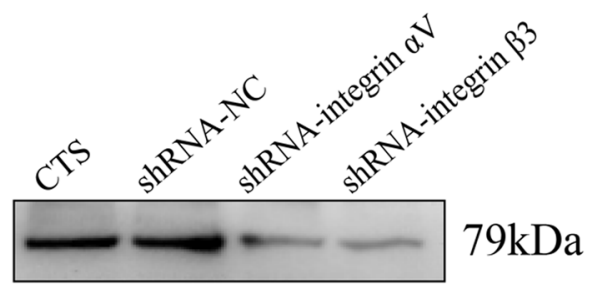

RUNX2

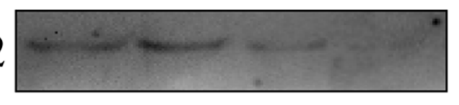

\section{GAPDH}

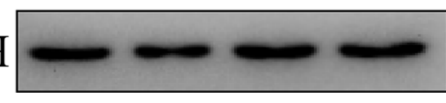

(d)

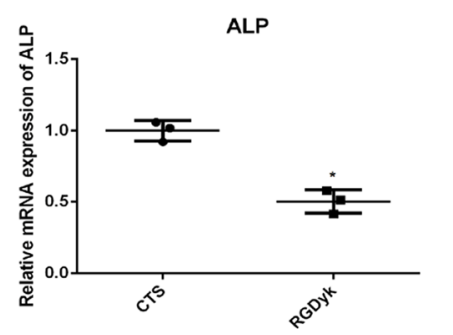

(f)

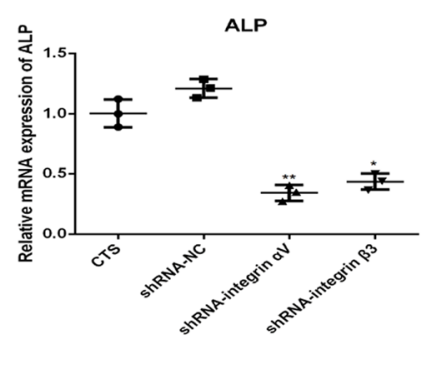

(b)
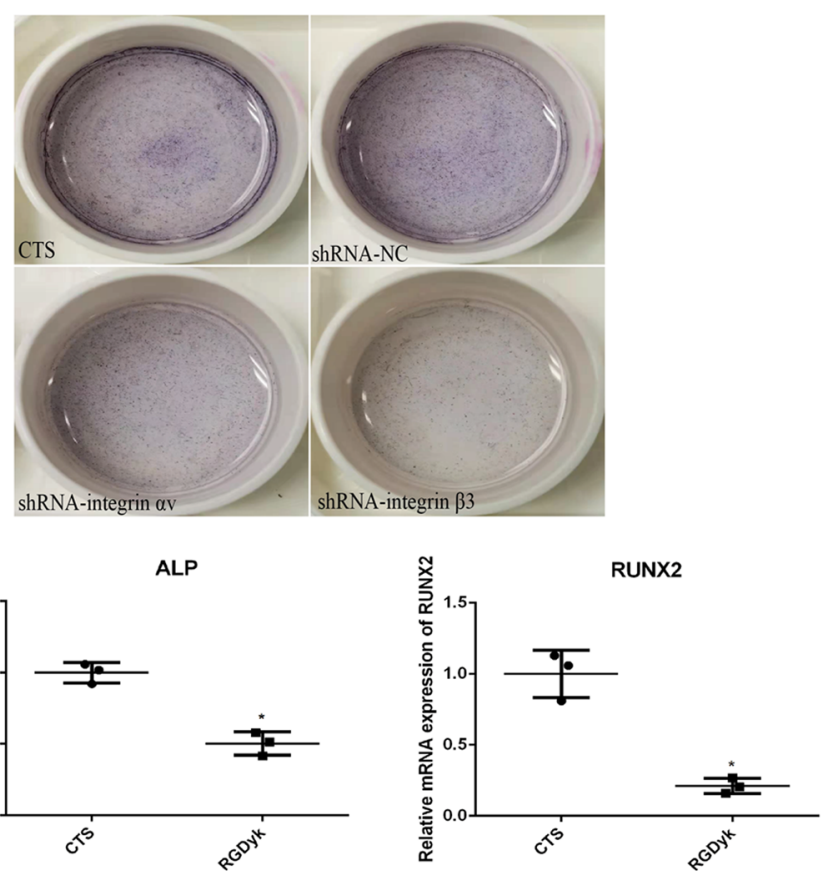

Fig. 2 CTS regulated cell proliferation and early stage of osteogenic differentiation of fibroblasts via integrin aV $\beta 3$. a Cell proliferation under CTS in the GM, NC, shRNA-integrin aV and shRNA-integrin $\beta 3$ groups. b ALP staining under CTS in the GM, NC, shRNA-integrin aV and shRNA-integrin $\beta 3$ groups. $\mathbf{c}$ Protein expression of ALP and RUNX2 under CTS in the GM and RGDyk groups. $\mathbf{d}$ mRNA expression of ALP and RUNX2 under CTS in the GM and RGDyk groups. e Protein expression of ALP and RUNX2 under CTS in the GM, NC, shRNA-integrin aV and shRNA-integrin $\beta 3$ groups. $\mathbf{f}$ mRNA expression of ALP and RUNX2 under CTS in the GM, NC, shRNA-integrin aV and shRNA-integrin $\beta 3$ groups

vinculin to explore their association with integrin $\alpha \mathrm{V} \beta 3$. Western blotting and qRT-PCR showed that expression of talin-1, FAK and vinculin increased under cyclic tensile stress (Fig. 5a, b). Western blotting showed that expression of talin-1, FAK and vinculin decreased when expression of integrin $\alpha \mathrm{V} \beta 3$ was inhibited by $\mathrm{c}$ (RGDyk) or shRNA (Fig. 5c, e). Similar results were obtained using qRT-PCR (Fig. 5d, f). Immunofluorescence showed that vinculin was more highly expressed and localized in visible focal adhesion plaques under cyclic tensile stress. Inhibition of integrin $\alpha V \beta 3$ was associated with a significant reduction in vinculin expression (Fig. $5 \mathrm{~g}$ ). These results suggest that cyclic tensile stress promotes formation of focal adhesions via integrin $\alpha \mathrm{V} \beta 3$.

Next, we investigated the role phosphorylation of FAK plays in osteogenic differentiation under cyclic tensile stress. Western blotting showed that phosphorylation of FAK increased in response to cyclic tensile stress, and inhibition of integrin $\alpha \mathrm{V} \beta 3$ downregulated phosphorylation of FAK (Fig. 5h, i). We found that when phosphorylation of FAK was inhibited by Y-15, a small molecule inhibitor, expression of ALP and RUNX2 was reduced (Fig. 5j, Additional file 2: Fig. S2c, Fig. S3). These results show that not only does FAK 


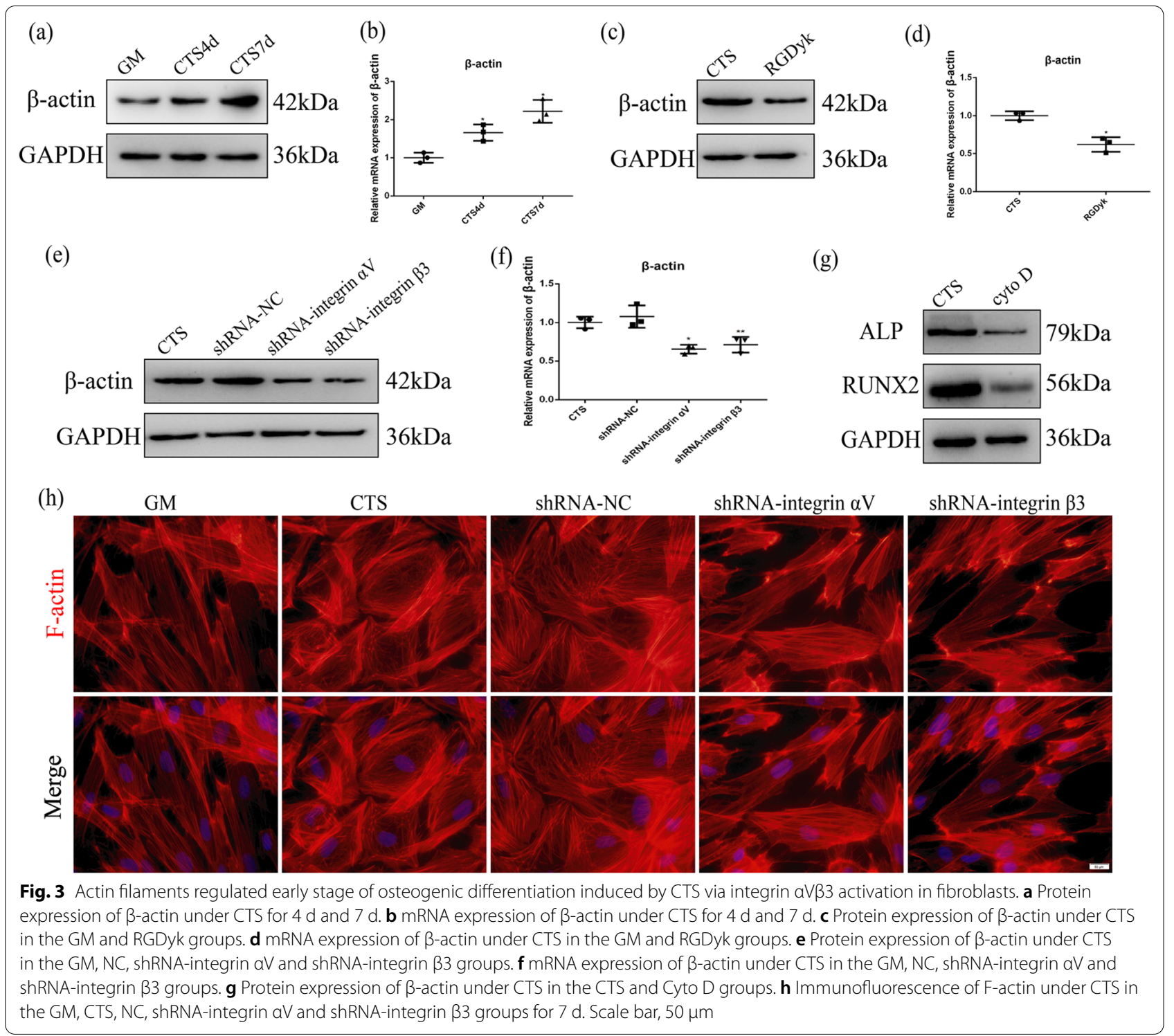

participate in the formation of focal adhesions containing integrin $\alpha \mathrm{V} \beta 3$ but also that phosphorylation of FAK contributes to early stage of osteogenic differentiation induced by cyclic tensile stress.

\section{Discussion}

Mechanotransduction is an important mechanism for regulating osteogenic differentiation of stem cells. Among various signaling pathways involved in osteogenic differentiation of stem cells, the ECM (extracellular matrix)-integrin-microfilament axis makes the greatest contribution to the response of stem cells to mechanical loading [31]. The present study showed that integrin $\alpha \mathrm{V} \beta 3$ contributed to early stage of osteogenic differentiation induced by cyclic tensile stress in fibroblasts.

Tensile stress has been shown to be an osteogenic stimulus for stem cells. In previous studies of the effects of tensile stress, stem cells were seeded onto a flexible membrane or within a matrix to which stress was applied [32-34]. Our study showed that cyclic tensile stress ( $10 \%$ strain, $0.5 \mathrm{~Hz}, 2 \mathrm{~h} / \mathrm{d})$ promotes cell proliferation and early stage of osteogenic differentiation of fibroblasts even without osteoblast-inducing conditioned media (Fig. 1a, b and Additional file 3: Fig. S3). However, differentiation of stem cells is dependent on characteristics of the applied tensile stress, including stress magnitude, frequency, and application time [35-38]. The relationship between tensile stress and 
(a)

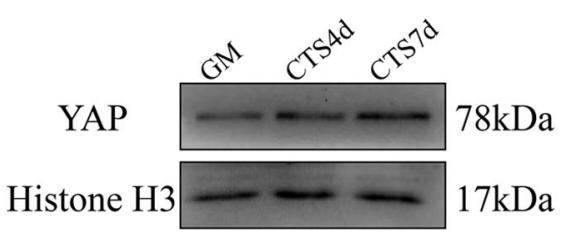

(b)

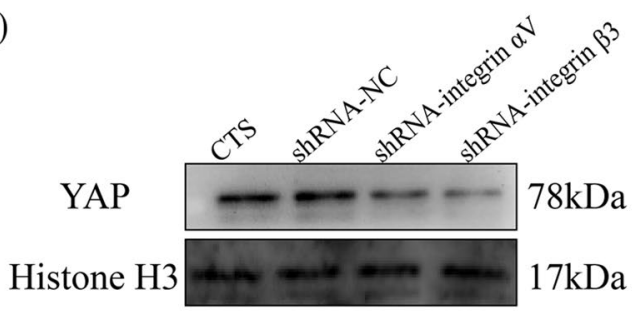

(c)

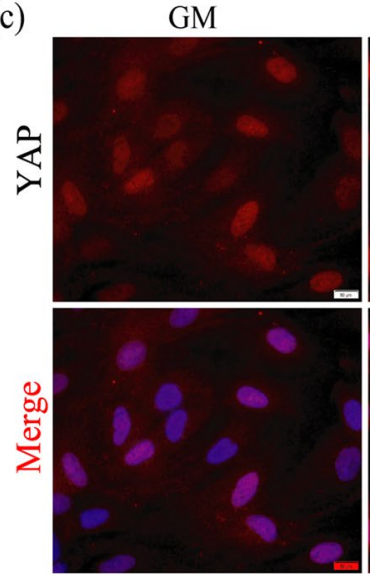

(d)
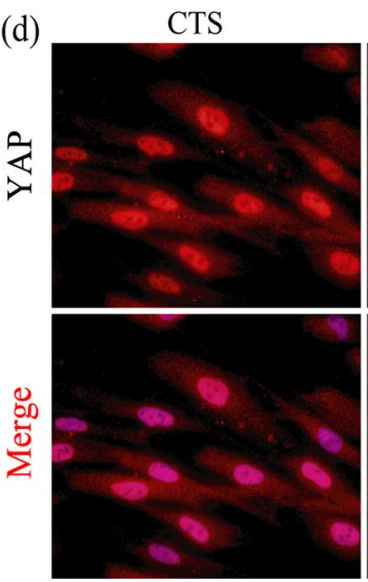

CTS

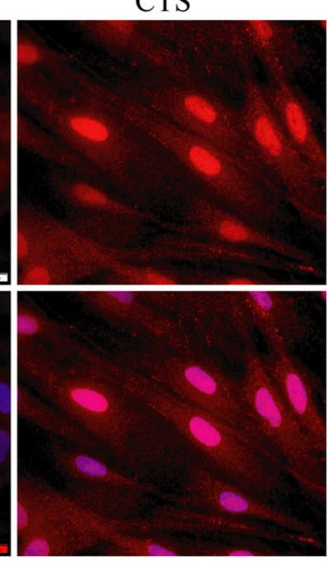

Cyto D

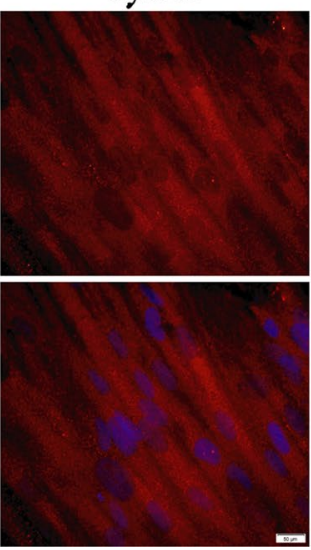

shRNA-integrin $\alpha \mathrm{V}$

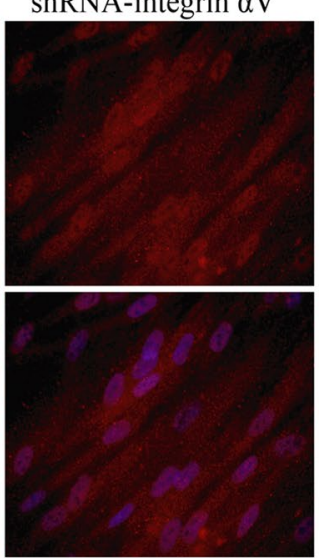

shRNA-integrin $\beta 3$

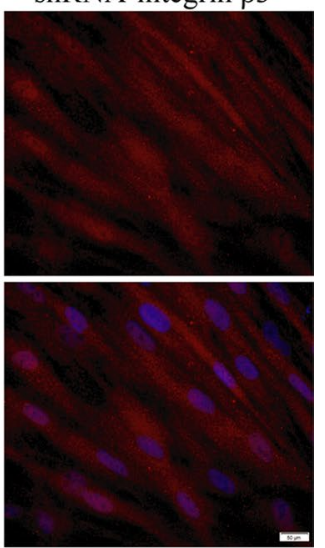

(e)

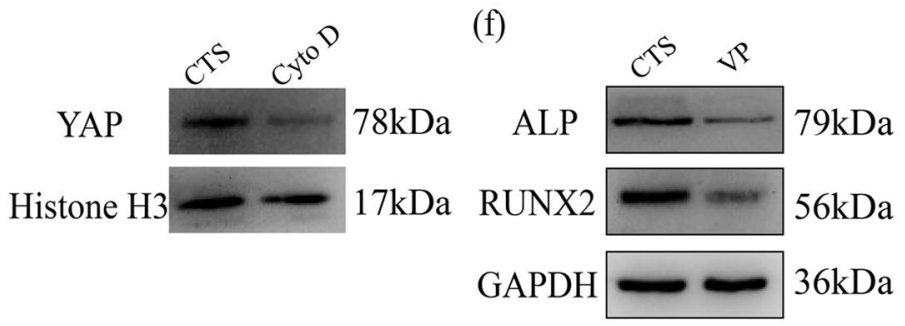

Fig. 4 Integrin aVB3 and actin filaments regulate expression of nuclear YAP during early stage of osteogenic differentiation induced by CTS. a Protein expression of nuclear YAP under CTS for $4 \mathrm{~d}$ and $7 \mathrm{~d}$. b Protein expression of nuclear YAP under CTS in the GM, NC, shRNA-integrin aV and shRNA-integrin $\beta 3$ groups. c Immunofluorescence of YAP under CTS in the GM, CTS, NC, shRNA-integrin aV and shRNA-integrin $\beta 3$ groups for $7 \mathrm{~d}$. Scale bar, $50 \mu \mathrm{m}$. d Immunofluorescence of YAP under CTS in the CTS and Cyto D groups for $7 \mathrm{~d}$. Scale bar, $50 \mu \mathrm{m}$. e Protein expression of nuclear YAP under CTS in the CTS and Cyto D groups. $\mathbf{f}$ Protein expression of ALP and RUNX2 under CTS in the CTS and VP groups

(See figure on next page.)

Fig. 5 Integrin aVB3 activation induced by CTS regulates focal adhesion-related proteins and phosphorylation of FAK to promote early stage of osteogenic differentiation. a Protein expression of talin-1, FAK and vinculin under CTS for $4 \mathrm{~d}$ and $7 \mathrm{~d}$. b mRNA expression of talin-1, FAK and vinculin under CTS for $4 \mathrm{~d}$ and $7 \mathrm{~d}$. c Protein expression of talin-1, FAK and vinculin under CTS in the GM and RGDyk groups. $\mathbf{d}$ mRNA expression of talin-1, FAK and vinculin under CTS in the GM and RGDyk groups. e Protein expression of talin-1, FAK and vinculin under CTS in the GM, NC, shRNA-integrin $a V$ and shRNA-integrin $\beta 3$ groups. $\mathbf{f}$ mRNA expression of talin-1, FAK and vinculin under CTS in the GM, NC, shRNA-integrin aV and shRNA-integrin $\beta 3$ groups. $\mathbf{g}$ Immunofluorescence of vinculin under CTS in the GM, CTS, NC, shRNA-integrin aV and shRNA-integrin $\beta 3$ groups for $7 \mathrm{~d}$. Scale bar, $50 \mu \mathrm{m}$. $\mathbf{h}$ Phosphorylation level of FAK under CTS for $7 \mathrm{~d}$. i Phosphorylation levels of FAK in the GM, NC, shRNA-integrin aV and shRNA-integrin $\beta 3$ groups under CTS. j Protein expression of ALP and RUNX2 in the CTS and Y15 groups under CTS 


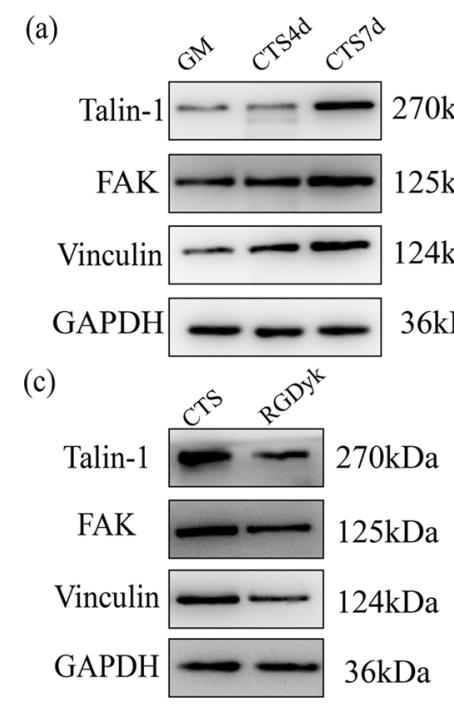

(b)
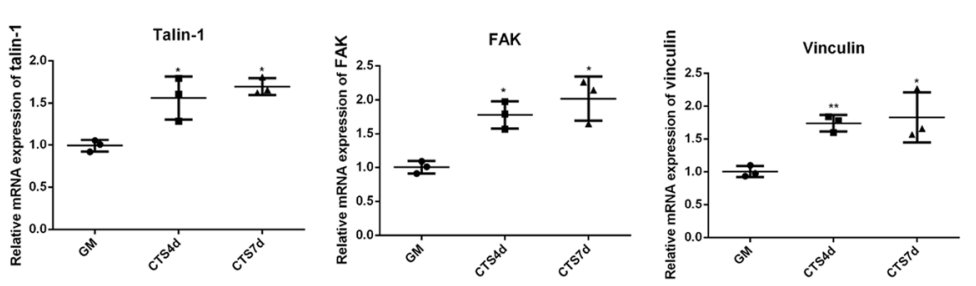

(d)

(e)
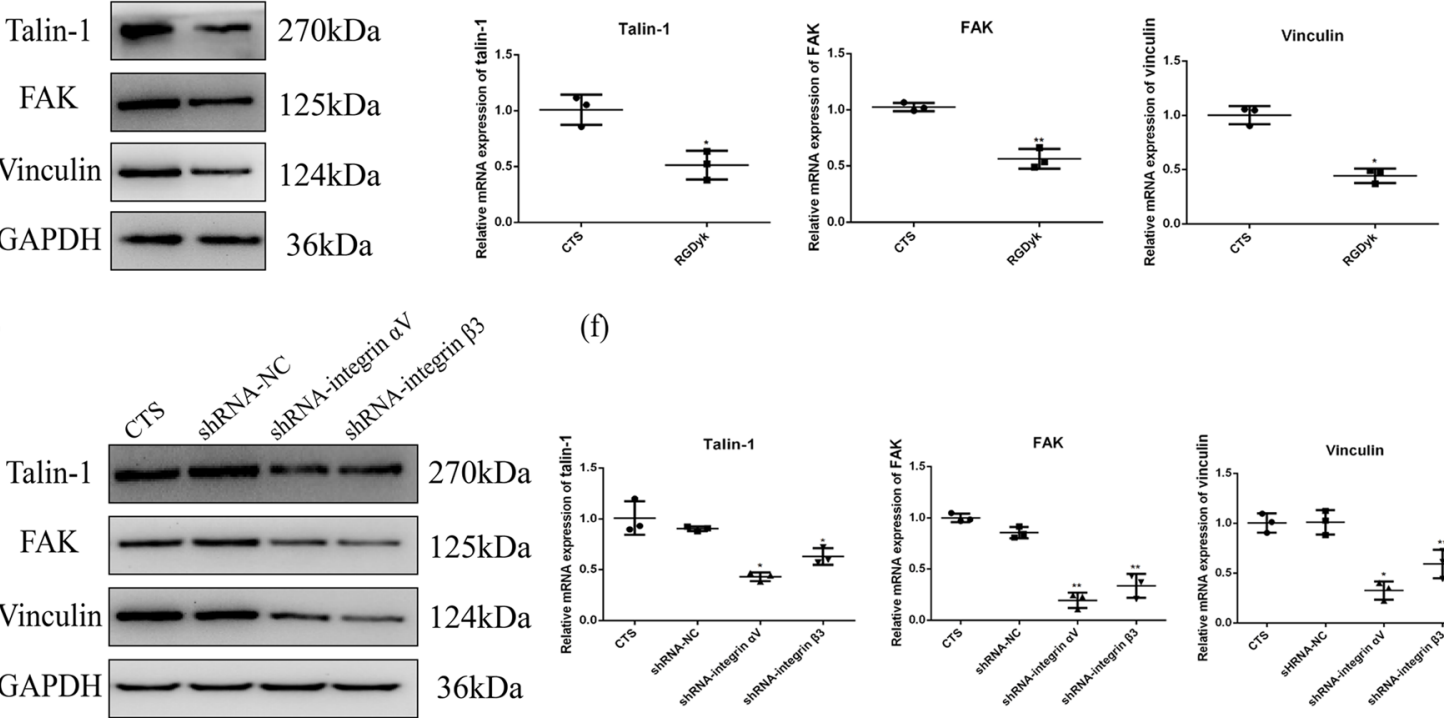

(f)

(g)
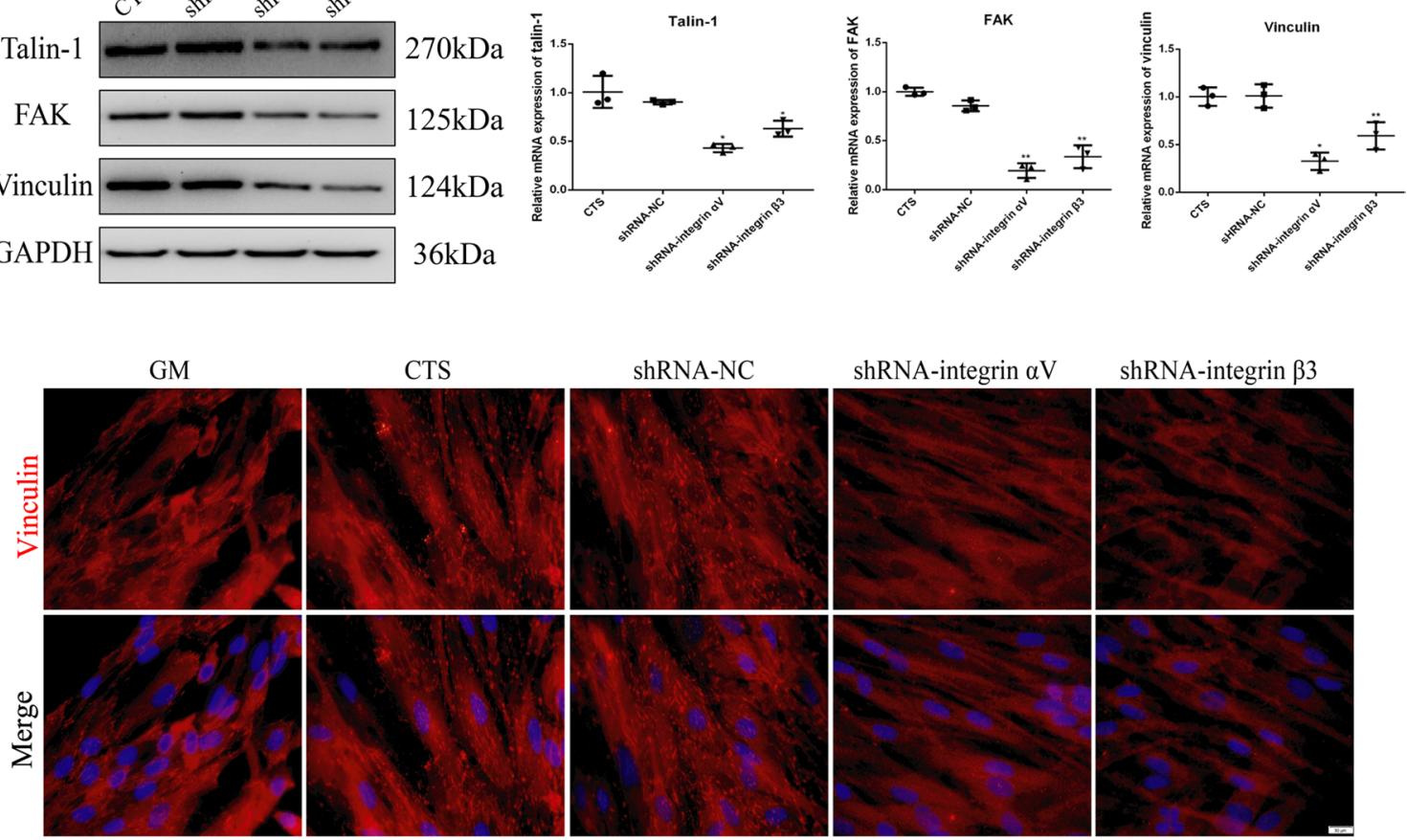

(h)

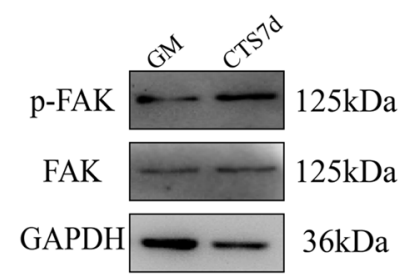

CTS

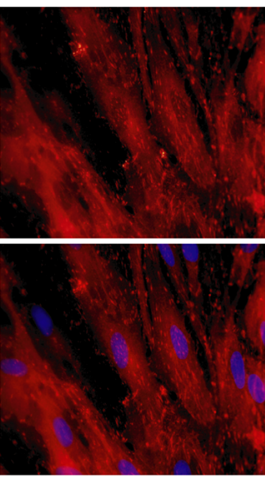

(i)

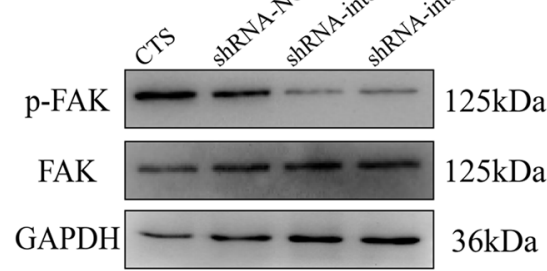

shRNA-NC

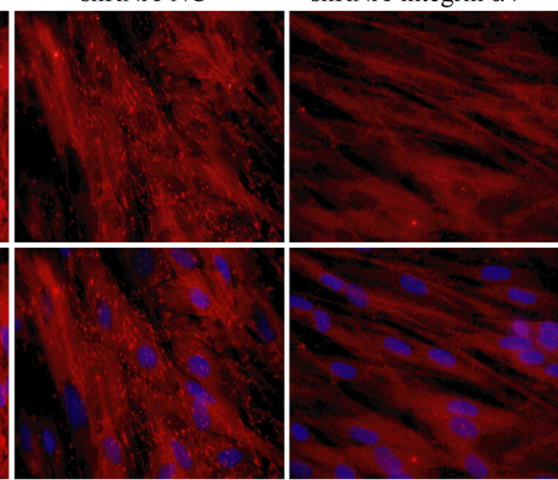

(j)

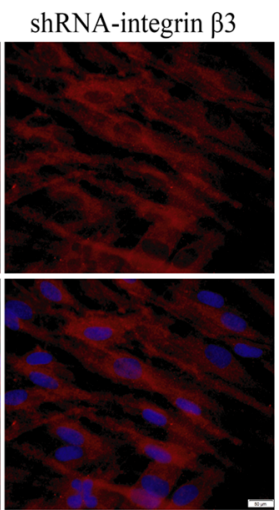

Fig. 5 (See legend on previous page.) 
osteogenic differentiation needs to be further explored. Research has shown that tensile stress can directly induce osteogenic differentiation of mesenchymal stem cells, but the specific targets of the tensile stress have yet to be fully characterized $[39,40]$. Studies have shown that integrin $\alpha \mathrm{V} \beta 3$ mediates expression of sclerostin by periostin and hence osteogenesis and survival in response to mechanical stimulation [41]. Therefore, we considered whether integrin $\alpha \mathrm{V} \beta 3$ plays a role in early stage of osteogenic differentiation induced by cyclic tensile stress.

Integrins connect to the intracellular actin cytoskeleton and provide a mechanical foundation for conduction of forces, cell shape stabilization, cell migration and differentiation [42]. Studies have shown that activation of integrin $\alpha \mathrm{V} \beta 3$ by mechanical loading upregulates the expression of c-fos, IGF-1 and COX-2, which can affect calcium influx in osteoblasts [43]. Activation of integrins from a low-affinity state to a high-affinity state is the basis of the formation of focal adhesions. Activation of integrins also recruits and activates adaptor proteins to form visible focal adhesion complexes [44]. The combination of integrins and ECM ligands activates multiple signaling pathways, including phosphorylation of enzymes, calcium influx and activation of the Rho pathway, which influence various aspects of cell physiological activity [42]. FAK is an indispensable part of focal adhesion structure, and the co-localization of FAK and integrins in focal adhesions is a prerequisite of FAK phosphorylation [45, 46]. It is likely that there are several signaling pathways responsible for mechanical signal transmission between cells and the ECM that regulate stem cell differentiation. It has been shown that FAK may be an important signaling protein that reacts to mechanical loading in complex signaling networks $[47,48]$. Our results show that integrin $\alpha \mathrm{V} \beta 3$ recruits talin, FAK and vinculin to form focal adhesions that promote osteogenic differentiation induced by cyclic tensile stress. Conversely, it has been reported that integrin $\alpha \mathrm{V} \beta 3$ affects osteoclast reabsorption by regulating cell polarity and cytoskeletal recombination [49]. Based on these results, we suggest that integrin $\alpha \mathrm{V} \beta 3$ plays an important role in bone physiology and the response to mechanical loading of osteocytes.

The microfilament cytoskeleton formed by actin polymerization plays an important role in osteogenic differentiation of mesenchymal stem cells [50]. The arrangement of the microfilament cytoskeleton is significantly altered during osteogenic differentiation. When stem cells differentiate into osteoblasts, the microfilament cytoskeleton becomes more dispersed as cells transform into osteoblasts [51]. Studies have shown that destruction of the microfilament cytoskeleton downregulates osteogenic differentiation induced by flow shear stress
[52]. Our study shows that rearrangement of the microfilament cytoskeleton contributes to early stage of osteogenic differentiation induced by cyclic tensile stress. In addition, the regulation of YAP by mechanical loading requires the microfilament cytoskeleton. Studies have shown that expression of nuclear YAP can be stimulated by actin polymerization [53-55]. The results of this study suggest that expression of nuclear YAP can be regulated by activation of the integrin $\alpha \mathrm{V} \beta 3$-microfilament axis under cyclic tensile stress. In addition, a recent study showed that YAP promotes osteogenic differentiation by regulating $\beta$-catenin signaling [56]. Therefore, we suggest that YAP plays different roles in multiple signaling pathways related to early stage of osteogenic differentiation.

\section{Conclusion}

Cyclic tensile stress exerts a positive effect on early stage of osteogenic differentiation of fibroblasts via integrin $\alpha \mathrm{V} \beta 3$ activation, leading to rearrangement of the microfilament cytoskeleton. Furthermore, rearrangement of actin filaments and phosphorylation of FAK stimulated by cyclic tensile stress via integrin $\alpha \mathrm{V} \beta 3$ lead to increased expression of nuclear YAP in human fibroblasts. In future studies, integrin $\alpha \mathrm{V} \beta 3$ should be considered a promising target for in vivo experiments to verify its function in the promotion of bone repair.

\section{Abbreviations}

ALP: Alkaline phosphatase; Cyto D: Cytochalasin D; CST: Cyclic tensile stress; ECM: Extracellular matrix; ECL: Enhanced chemiluminescence; FAK: Focal adhesion kinase; GAPDH: Glyceraldehyde-3-phosphate dehydrogenase; GM: Growth medium; NC: Negative control; PBS: Phosphate-buffered saline; PVDF: Polyvinylidene difluoride; RUNX2: Runt-related transcription factor 2; TEAD: TEA domain DNA-binding family of transcription factors; VP: Verteporfin; YAP: Yes-associated protein.

\section{Supplementary Information}

The online version contains supplementary material available at https://doi. org/10.1186/s13287-021-02597-y.

Additional file 1: Fig. S1. The function of integrin aVB3 was inhibited by $c($ RGDyk) $(10 \mu \mathrm{M})(\mathrm{a})$ and Lentivirus transduction (b, c).

Additional file 2: Fig. S2. (a) Polymerization of $\beta$-actin was inhibited by cytochalasin D $(0.2 \mu \mathrm{g} / \mathrm{mL})$. (b) The function of nuclear YAP was inhibited by verteporfin $(5 \mu \mathrm{M})$. (c) Phosphorylation of FAK was inhibited by Y-15 (2 $\mu \mathrm{M})$.

Additional file 3: Fig. S3. Adipogenic differentiation and Chondrogenic differentiation in fibroblasts under CTS. (a) Oil-red O staining under CTS for $7 \mathrm{~d}$. (b) Toluidine blue staining under CTS for $7 \mathrm{~d}$.

Additional file 4: Fig. S4. Original images of western blots.

\section{Acknowledgements}

Not applicable.

\section{Authors' contributions}

J.O., and J.D contributed to conceptualization and methodology. Y.P., R.Q., Y. F., Y.Y., T.F., X.H., B.S., A.U.K., S.W were involved in investigation. Y.P., J.D contributed 
to formal analysis. Y.P., J.D. and J.O were involved in writing - review and editing. All authors read and approved the final manuscript.

\section{Funding}

This study was funded by the National Key R\&D Program of China (\#2017YFC 1 105000), and Guangdong Provincial Key Laboratory of Medical Biomechanics Opens Operation (\#2017B030314039).

\section{Availability of data and materials}

All the supporting data can be downloaded.

\section{Declarations}

Ethics approval and consent to participate Not applicable.

\section{Informed consent}

Not applicable.

\section{Competing interests}

The authors declare that they have no competing interests.

\section{Author details}

${ }_{1}^{1}$ Guangdong Provincial Key Laboratory of Medical Biomechanics and Department of Anatomy, School of Basic Medical Science, Southern Medical University, Guangzhou 510000, China. ${ }^{2}$ Department of Ophthalmology, The First Affiliated Hospital of Guangzhou Medical University, Guangzhou 510000, Guangdong, China.

Received: 25 April 2021 Accepted: 11 July 2021

Published online: 07 October 2021

\section{References}

1. Khan SN, Cammisa FJ, Sandhu HS, Diwan AD, Girardi FP, Lane JM. The biology of bone grafting. J Am Acad Orthop Surg. 2005;13:77-86.

2. Schemitsch EH. Size matters: defining critical in bone defect size! J Orthop Trauma. 2017;31(Suppl 5):S20-2.

3. Oryan A, Alidadi S, Moshiri A, Maffulli N. Bone regenerative medicine: classic options, novel strategies, and future directions. J Orthop Surg Res. 2014;9:18.

4. Hosseinkhani M, Mehrabani D, Karimfar MH, Bakhtiyari S, Manafi A, Shirazi R. Tissue engineered scaffolds in regenerative medicine. World J Plast Surg. 2014;3:3-7.

5. Peric KZ, Rider P, Alkildani S, Retnasingh S, Pejakic M, Schnettler R, et al. An introduction to bone tissue engineering. Int J Artif Organs. 2020:43:69-86.

6. Tracy LE, Minasian RA, Caterson EJ. Extracellular matrix and dermal fibroblast function in the healing wound. Adv Wound Care (New Rochelle). 2016;5:119-36.

7. Denu RA, Nemcek S, Bloom DD, Goodrich AD, Kim J, Mosher DF, et al. Fibroblasts and mesenchymal stromal/stem cells are phenotypically indistinguishable. Acta Haematol. 2016;136:85-97.

8. LV FJ, Tuan RS, Cheung KM, Leung VY. Concise review: the surface markers and identity of human mesenchymal stem cells. Stem Cells. 2014:32:1408-19.

9. Micha D, Voermans E, Eekhoff M, van Essen HW, Zandieh-Doulabi B, Netelenbos C, et al. Inhibition of TGFbeta signaling decreases osteogenic differentiation of fibrodysplasia ossificans progressiva fibroblasts in a novel in vitro model of the disease. Bone. 2016;84:169-80.

10. Cho Y, Kim B, Bae H, Kim W, Baek J, Woo K, et al. Direct gingival fibro blast/osteoblast transdifferentiation via epigenetics. J Dent Res. 2017:96:555-61.

11. Yu F, Cui Y, Zhou X, Zhang X, Han J. Osteogenic differentiation of human ligament fibroblasts induced by conditioned medium of osteoclast-like cells. Biosci Trends. 2011;5:46-51.

12. Aloise AC, Pereira MD, Duailibi SE, Gragnani A, Ferreira LM. TGF-beta1 on induced osteogenic differentiation of human dermal fibroblast. Acta Cir Bras. 2014;29(Suppl 1):1-6.
13. Claeys L, Bravenboer N, Eekhoff E, Micha D. Human fibroblasts as a model for the study of bone disorders. Front Endocrinol (Lausanne). 2020;11:394.

14. Gomez S, Vlad MD, Lopez J, Fernandez E. Design and properties of 3D scaffolds for bone tissue engineering. Acta Biomater. 2016;42:341-50.

15. Lee JM, Kim MG, Byun JH, Kim GC, Ro JH, Hwang DS, et al. The effect of biomechanical stimulation on osteoblast differentiation of human jaw periosteum-derived stem cells. Maxillofac Plast Reconstr Surg. 2017;39:7.

16. Grier WG, Moy AS, Harley BA. Cyclic tensile strain enhances human mesenchymal stem cell Smad 2/3 activation and tenogenic differentiation in anisotropic collagen-glycosaminoglycan scaffolds. Eur Cell Mater. 2017;33:227-39.

17. Ross TD, Coon BG, Yun S, Baeyens N, Tanaka K, Ouyang M, et al. Integrins in mechanotransduction. Curr Opin Cell Biol. 2013;25:613-8.

18. Humphries JD, Byron A, Humphries MJ. Integrin ligands at a glance. J Cell Sci. 2006;119:3901-3.

19. Legate KR, Wickstrom SA, Fassler R. Genetic and cell biological analysis of integrin outside-in signaling. Genes Dev. 2009;23:397-418.

20. Chen Q, Shou P, Zhang L, Xu C, Zheng C, Han Y, et al. An osteopontinintegrin interaction plays a critical role in directing adipogenesis and osteogenesis by mesenchymal stem cells. Stem Cells. 2014;32:327-37.

21. Stange R, Kronenberg D, Timmen M, Everding J, Hidding H, Eckes B, et al. Age-related bone deterioration is diminished by disrupted collagen sensing in integrin alpha2beta1 deficient mice. Bone. 2013;56:48-54.

22. Campbell ID, Humphries MJ. Integrin structure, activation, and interactions. Cold Spring Harb Perspect Biol. 2011;3:a004994.

23. Harburger DS, Calderwood DA. Integrin signalling at a glance. J Cell Sci. 2009;122:159-63.

24. Shattil SJ, Kim C, Ginsberg MH. The final steps of integrin activation: the end game. Nat Rev Mol Cell Biol. 2010;11:288-300.

25. Plouffe SW, Lin KC, Moore JR, Tan FE, Ma S, Ye Z, et al. The Hippo pathway effector proteins YAP and TAZ have both distinct and overlapping functions in the cell. J Biol Chem. 2018;293:11230-40.

26. Sun C, De Mello V, Mohamed A, Ortuste QH, Garcia-Munoz A, Al BA, et al. Common and distinctive functions of the hippo effectors Taz and Yap in Skeletal muscle stem cell function. Stem Cells. 2017;35:1958-72.

27. Zhao B, Ye X, Yu J, Li L, Li W, Li S, et al. TEAD mediates YAP-dependent gene induction and growth control. Genes Dev. 2008;22:1962-71.

28. Dupont S, Morsut L, Aragona M, Enzo E, Giulitti S, Cordenonsi M, et al. Role of YAP/TAZ in mechanotransduction. Nature. 2011;474:179-83.

29. Shoji K, Ohashi K, Sampei K, Oikawa M, Mizuno K. Cytochalasin D acts as an inhibitor of the actin-cofilin interaction. Biochem Biophys Res Commun. 2012:424:52-7.

30. Flanagan MD, Lin S. Cytochalasins block actin filament elongation by binding to high affinity sites associated with F-actin. J Biol Chem. 1980;255:835-8.

31. Dufour C, Holy X, Marie PJ. Transforming growth factor-beta prevents osteoblast apoptosis induced by skeletal unloading via PI3K/Akt, $\mathrm{BCl}-2$, and phospho-Bad signaling. Am J Physiol Endocrinol Metab. 2008;294:E794-801.

32. Wang J, Wang CD, Zhang N, Tong WX, Zhang YF, Shan SZ, et al. Mechanical stimulation orchestrates the osteogenic differentiation of human bone marrow stromal cells by regulating HDAC1. Cell Death Dis. 2016; 7:e2221.

33. Shin JW, Wu Y, Kang YG, Kim JK, Choi HJ, Shin JW. The effects of epigallocatechin-3-gallate and mechanical stimulation on osteogenic differentiation of human mesenchymal stem cells: individual or synergistic effects. Tissue Eng Regen Med. 2017;14:307-15.

34. Wu J, Zhao J, Sun L, Pan Y, Wang H, Zhang WB. Long non-coding RNA H19 mediates mechanical tension-induced osteogenesis of bone marrow mesenchymal stem cells via FAK by sponging miR-138. Bone. 2018;108:62-70.

35. Jagodzinski M, Drescher M, Zeichen J, Hankemeier S, Krettek C, Bosch U, et al. Effects of cyclic longitudinal mechanical strain and dexamethasone on osteogenic differentiation of human bone marrow stromal cells. Eur Cell Mater. 2004;7(35-41):41.

36. Zhang $P, W u Y$, Jiang $Z$, Jiang $L$, Fang B. Osteogenic response of mesenchymal stem cells to continuous mechanical strain is dependent on ERK1/2-Runx2 signaling. Int J Mol Med. 2012;29:1083-9.

37. Sumanasinghe RD, Bernacki SH, Loboa EG. Osteogenic differentiation of human mesenchymal stem cells in collagen matrices: effect of uniaxial 
cyclic tensile strain on bone morphogenetic protein (BMP-2) mRNA expression. Tissue Eng. 2006;12:3459-65.

38. Koike M, Shimokawa H, Kanno Z, Ohya K, Soma K. Effects of mechanical strain on proliferation and differentiation of bone marrow stromal cell line ST2. J Bone Miner Metab. 2005;23:219-25.

39. Qi MC, Hu J, Zou SJ, Chen HQ, Zhou HX, Han LC. Mechanical strain induces osteogenic differentiation: Cbfa1 and Ets-1 expression in stretched rat mesenchymal stem cells. Int J Oral Maxillofac Surg. 2008:37:453-8.

40. Friedl G, Schmidt H, Rehak I, Kostner G, Schauenstein K, Windhager R. Undifferentiated human mesenchymal stem cells (hMSCs) are highly sensitive to mechanical strain: transcriptionally controlled early osteo-chondrogenic response in vitro. Osteoarthritis Cartilage. 2007:15:1293-300.

41. Wu D, Schaffler MB, Weinbaum S, Spray DC. Matrix-dependent adhesion mediates network responses to physiological stimulation of the osteocyte cell process. Proc Natl Acad Sci U S A. 2013;110:12096-101.

42. Fassler R, Meyer M. Consequences of lack of beta 1 integrin gene expression in mice. Genes Dev. 1995;9:1896-908.

43. Miyauchi A, Gotoh M, Kamioka H, Notoya K, Sekiya H, Takagi Y, et al. AlphaVbeta3 integrin ligands enhance volume-sensitive calcium influx in mechanically stretched osteocytes. J Bone Miner Metab. 2006;24:498-504.

44. Katsumi A, Orr AW, Tzima E, Schwartz MA. Integrins in mechanotransduction. J Biol Chem. 2004;279:12001-4.

45. Shen Y, Schaller MD. Focal adhesion targeting: the critical determinant of FAK regulation and substrate phosphorylation. Mol Biol Cell. 1999:10:2507-18.

46. Tahiliani PD, Singh L, Auer KL, LaFlamme SE. The role of conserved amino acid motifs within the integrin beta3 cytoplasmic domain in triggering focal adhesion kinase phosphorylation. J Biol Chem. 1997;272:7892-8.

47. Schneider GB, Zaharias R, Stanford C. Osteoblast integrin adhesion and signaling regulate mineralization. J Dent Res. 2001;80:1540-4.

48. Xiao G, Jiang D, Thomas P, Benson MD, Guan K, Karsenty G, et al. MAPK pathways activate and phosphorylate the osteoblast-specific transcription factor, Cbfa1. J Biol Chem. 2000;275:4453-9.
49. Faccio R, Novack DV, Zallone A, Ross FP, Teitelbaum SL. Dynamic changes in the osteoclast cytoskeleton in response to growth factors and cell attachment are controlled by beta3 integrin. J Cell Biol. 2003;162:499-509.

50. Huang X, Qu R, Peng Y, Yang Y, Fan T, Sun B, Khan AU, Wu S, Wei K, Xu C, Dai J, Ouyang J, Zhong S. Mechanical sensing element PDLIM5 promotes osteogenesis of human fibroblasts by affecting the activity of microfilaments. Biomolecules. 2021;11(5):759.

51. Rodriguez JP, Gonzalez M, Rios S, Cambiazo V. Cytoskeletal organization of human mesenchymal stem cells (MSC) changes during their osteogenic differentiation. J Cell Biochem. 2004;93:721-31.

52. Arnsdorf EJ, Tummala P, Kwon RY, Jacobs CR. Mechanically induced osteogenic differentiation - the role of RhoA, ROCKII and cytoskeletal dynamics. J Cell Sci. 2009;122:546-53.

53. Zhao B, Li L, Wang L, Wang CY, Yu J, Guan KL. Cell detachment activates the Hippo pathway via cytoskeleton reorganization to induce anoikis. Genes Dev. 2012;26:54-68.

54. Machesky LM, Hall A. Role of actin polymerization and adhesion to extracellular matrix in Rac- and Rho-induced cytoskeletal reorganization. J Cell Biol. 1997:138:913-26.

55. Hotchin NA, Hall A. The assembly of integrin adhesion complexes requires both extracellular matrix and intracellular rho/rac GTPases. J Cell Biol. 1995;131:1857-65.

56. Pan JX, Xiong L, Zhao K, Zeng P, Wang B, Tang FL, et al. YAP promotes osteogenesis and suppresses adipogenic differentiation by regulating beta-catenin signaling. Bone Res. 2018;6:18.

\section{Publisher's Note}

Springer Nature remains neutral with regard to jurisdictional claims in published maps and institutional affiliations.
Ready to submit your research? Choose BMC and benefit from:

- fast, convenient online submission

- thorough peer review by experienced researchers in your field

- rapid publication on acceptance

- support for research data, including large and complex data types

- gold Open Access which fosters wider collaboration and increased citations

- maximum visibility for your research: over $100 \mathrm{M}$ website views per year

At BMC, research is always in progress.

Learn more biomedcentral.com/submissions 